\title{
Sobre héroes e ideologías: la construcción del sujeto en la literatura perteneciente al campo cultural afín a la dictadura*
}

On heroes and ideologies: the construction of the subject in the literature pertaining to the cultural field related to the dictatorship

\author{
Carla Rojas Valenzuela
}

Facultad de filosofía y humanidades, Universidad de Chile. Dirección postal: Serrano 266, departamento 714, Santiago, Santiago. Chile.

Correo electrónico: rojas.carla.v@gmail.com

\begin{abstract}
El propósito de este artículo es indagar en la literatura escrita dentro del campo cultural afín a la dictadura durante la década de los ochenta. Si bien es innegable la aparición de principios comunes entre estas obras, existen también notables diferencias que responden, principalmente, a las discrepancias ideológicas que dividieron a los adherentes del régimen. En ese sentido, nuestro análisis apunta develar cómo las formas de representación utilizadas en la producción de estos textos, puntualmente aquellas enfocadas en la configuración de los sujetos y su medio, grafican la distancia y ponen de manifiesto un conflicto angular dentro del pensamiento autoritario chileno.
\end{abstract}

Palabras clave: héroes, dictadura, nacionalismo, neoliberalismo.

The purpose of this article is to investigate written literature within the cultural field related to the dictatorship during the eighties decade. While the appeareance of common principles is undeniable among these works, there are also notable differences associated with ideological disagreements that divided its adherents. In that sense, our analysis points to reveal how the forms of representation used in the production of these texts, mainly those focused on the configuration of the subject and his environment, depict this distance and show the angular conflict within the Chilean authoritarian thinking.

Key words: heroes, dictatorship, nationalism, neoliberalism.

El presente artículo es parte de la investigación "Despolitizar la literatura, reescribir la historia: los usos del romance en las novelas de la dictadura", correspondiente a mi tesis para optar al grado de magíster en literatura, otorgado por la Universidad de Chile, 2015. 


\section{INTRODUCCIÓN}

Aproximarse a la producción cultural que emerge en el campo proclive a la dictadura chilena es siempre una tarea compleja, pues además de ser escasa, también fue, para la crítica, de poca calidad. En conjunto estos aspectos determinaron el hecho de que, tras el retorno a la democracia, la gran mayoría de las obras que emergieron desde aquel nicho cultural fuesen castigadas con el olvido y la indiferencia. Un buen ejemplo de ello son las novelas publicadas en el periodo por sujetos que se identificaron, de una u otra forma, con la administración golpista; la configuración de las obras es significativa para explorar las lógicas de producción cultural predominantes en la época y las corrientes de pensamiento que subyacen a ellas. Conforme a ello, el presente estudio abarca dos textos publicados en la década de los ochenta: Dónde estás, Constanza... (1981) de José Luis Rosasco y Águilas y cóndores (1986) de Enrique Campos Menéndez. El primero es, de seguro, el texto ligado a esta esfera con mayor visibilidad, pues su incorporación al currículum escolar lo convirtió en lectura recurrente para los adolescentes chilenos hasta entrado el siglo XXI; el segundo tuvo mucho menor trascendencia. No obstante, la notoriedad mediática vendrá, tangencialmente, tras la polémica entrega del premio nacional de literatura a su autor en 1986.

En ambas obras nos encontramos frente a la expresión del romance -hibridado con elementos propios del melodrama, la narrativa folletinesca y la novela modernacomo género literario predominante. En base a ello, importa señalar que si bien el romance ha tenido ciertas particularidades asociadas a su contexto de producción, una de sus principales características se relaciona con que las convenciones de las que se hace cargo muestran "pocos cambios a lo largo de los siglos, y un conservadurismo de este tipo es señal de un género estable" (Frye 1991: 12). De esta manera, la secuencia de enamoramiento, desencuentros, separación, aventuras, reencuentro y consumación del amor que le es inherente se mantiene casi inalterable a través de la historia.

Utilizaremos aquí el concepto haciéndonos cargo de ello y, a su vez, entendiéndolo de forma amplia como historia de amor escrita en prosa, cuyo foco es la situación de noviazgo, compromiso o enamoramiento entre una o más parejas (Regis 2007: 19). Los textos que se escribieron a partir del esquema y propiedades ofrecidas por este género fueron diferenciados de la novela moderna por ser considerados más alegóricos que los últimos (Sommer 2004: 22). En consecuencia, se irá configurando una división en la que la novela adquiere una valoración social positiva como objeto de goce estético mediante el cual se puede acceder a un conocimiento del mundo, en otras palabras, se significa como "literatura seria", mientras que el romance pasa a ser considerado como objeto de consumo y adquiere el estatus de infraliteratura, destinado a la diversión de masas (Frye 1991: 15).

Durante el siglo XX los textos que cumplieron con estas propiedades fueron agrupados bajo el rótulo de novelas rosa y aquí utilizaremos dicho concepto como sinónimo de romance, teniendo en cuenta las consideraciones contextuales hechas anteriormente y, sobre todo, las características de los textos que aquí nos ocupan ${ }^{1}$.

Concordamos con N. Frye en que "en toda época de la historia, la sociedad acepta e incorpora a su literatura seria ciertos valores predominantes. Habitualmente, este proceso incluye alguna forma de romance secuestrado, es decir, fórmulas del romance empleadas para reflejar determinados valores predominantes, religiosos o sociales" (Frye 
Ahora bien, el amor es aquí concebido como antítesis del tratamiento de lo explícitamente político y, sobre todo, como forma de elusión del presente de producción, pues cualquier referencia directa al contexto inmediato en las obras las convertía en un mero panfleto ${ }^{2}$. Apropiándose del discurso oficial ${ }^{3}$, la despolitización de la literatura vio en el romance la posibilidad de difundir valores y principios acordes a la dictadura; la secuencia en la que se describen las uniones y desencuentros entre las parejas protagonistas sigue un curso, más o menos, similar en los argumentos de las obras. Sin embargo, no todo en estas novelas son coincidencias, al igual que en el campo de poder, existen en ellas diferencias que ponen de manifiesto, sin titubeos, las oposiciones entres principales corrientes de pensamiento vigentes en la derecha chilena de la época: nacionalismo y neoliberalismo.

Este último generó férrea resistencia en algunos de los partidarios de la dictadura, que habían visto en la acción militar el remedio frente a la degradación de la esencia nacional a causa del socialismo. Desde esta perspectiva es interesante, a mi juicio, observar cómo se resuelve la encrucijada que significa la tensión entre dos paradigmas económico-sociales que chocan en asuntos tan esenciales como lo es rol del Estado en la educación, en el contexto que ofrece la construcción de una cultura cuyos principales rasgos deben ahora afirmarse en un capital simbólico más que en uno factual.

Es en ese sentido que, atendiendo al conflicto que supuso la puesta en marcha del modelo neoliberal en el contexto chileno, el presente artículo pretende abordar la relación que se da entre el imaginario asociado a los modos de producción inherentes a él y los modos de producción literaria que aparecen en las tres obras seleccionadas. Lo que intento hacer notar a través de esta aproximación es el hecho de que la posición adoptada por los actores culturales respecto de la configuración ideológica en pugna dentro del campo de poder y, consecutivamente, del campo cultural, determinará las principales diferencias y convergencias observables en los mecanismos de representación presentes en los textos.

Para ello nos enfocaremos, puntualmente, en el análisis de los héroes que protagonizan cada una de las obras en cuestión, haciéndonos cargo del proceso de particularización y definición de los rasgos de cada uno de estos personajes, como paso previo al establecimiento de categorías que permitan dar a conocer los constructos ideológicos que subyacen a su elaboración. Por último, en base a esta

1991: 43). No obstante, algo peculiar en los ejemplos que estamos trabajando es que, más allá de la extrapolación de algunos elementos útiles del romance al presente de producción de los autores, se evidencia en sus respectivos textos una aplicación casi inalterada de la estructura y propiedades del relato inherente al género, en un contexto general en el cual las condiciones histórico-literarias se dirigen con claridad hacia horizontes diametralmente diferentes. Beatriz Sarlo evidencia un fenómeno similar en Argentina, en publicaciones de comienzos de siglo XX: "Opuestas a las vanguardias... estas narraciones semanales ponían en circulación formas estéticas anteriores a las del momento de su publicación. Formas extraídas de la literatura modernista o tardorromántica” (2011: 26).

2 Así lo señalaría explícitamente Rosasco: "No estoy entre los escritores que instrumentalizan la literatura hacia determinados propósitos. Sí entre los que creen que su territorio es el pasado. Creo que el presente lo cubre mejor el periodismo, la economía o la política por ejemplo" (Rosasco 1984: E5)

Conviene puntualizar, tal y como señala Isabel Jara, que el axioma "despolitizador" será compartido por el nacionalismo, el gremialismo y la Doctrina de Seguridad Nacional; estableciendo en el tiempo una estrecha dependencia con "el neoliberalismo, porque este requería de dicha "despolitización" para justificarse mientras que aquella requería del individualismo extremo para realizarse” (2015: 519). 
operación, reflexionaremos en torno al valor y significado que tiene para el campo cultural la adopción de uno u otro pensamiento sociopolítico.

\section{NOSOTROS Y LOS OTROS}

El examen del sustrato político y cultural desde el cual es configurado un héroe debe partir, necesariamente, por la particularización que se hace de él en su propio escenario, pues, si bien existe un patrón común al héroe del romance, asociado a la secuencia de aventuras que vive (Frye 1991: 79), no es posible prescindir de la heterogeneidad ideológica que configura interesantes matices en las obras. Las marcas textuales que se asocian a ésta se transforman en muestras elocuentes del inconsciente político (Jameson 1989: 16) de cada obra y, por ende, son objeto de nuestro interés. Conforme a ello, caracterizaremos brevemente a estos protagonistas, para luego establecer los nudos problemáticos en torno a los cuales se articulará nuestro argumento.

En Dónde estás, Constanza... el protagonista es Alex Corsiglia, un adolescente que vive en la comuna de Nuñoa en los años cincuenta ${ }^{4}$, época en la cual este era considerado un barrio bastante acomodado y exclusivo (Rosasco 1981: 9). En el transcurso de la obra tanto el protagonista como su familia son escasamente descritos en términos físicos o psicológicos, situación que se contrapone radicalmente a la de los recién llegados Glicker, a quienes se les muestra con mayor detalle: "En un rincón ... sentada sobre una mesita con cajón o un velador o algo así, venía una chica con un vestido largo de muselina verde, y un abanico que aleteaba cadenciosamente en su mano y detrás del cual se pronunciaba entre aleteo y aleteo, y enmarcada por rizos negros, negrísimos, la carita más blanca y más linda que Alex había visto en su vida" (Rosasco 1981: 11).

No obstante, la carencia de referencias en torno al héroe no es un obstáculo para conocerlo, dado que el vacío se suple con la descripción del espacio físico que le es propio:

Desde la casa de Alex Corsiglia era posible, en esos años, contemplar la aparición del sol ... Ñuñoa era entonces el Barrio Alto y no pocos de sus habitantes se sentían sobradamente orgullosos de residir allí; de manera que la forma en que los Glicker llegaron al vecindario tenía que escandalizar a muchos. No se concebía que una familia decente se mudara en un carretón como aquel ... La carretela en la que llegaron los Glicker ni siquiera disponía de ruedas de goma; las que tenía eran de madera ... Y el hecho inverosímil de que los Glicker, la familia entera, vinieran arriba del carretón ya era más que suficiente para suscitar el estupor del más impertérrito de los ñuñoínos (Rosasco 1981: 9-10).

Las características que el narrador asigna a la comuna de Ñuñoa debiesen bastar para dar cuenta de que los Corsiglia, y Alex particularmente, son coincidentes con ese paisaje, mientras que los foráneos resaltan pues dan cuenta de una imagen anómala; de ahí que unos ameriten ser particularizados y otros no. El conflicto del cual da cuenta el párrafo citado contrapone los conceptos de orgullo y decencia, dimensiones abstractas sobre las que se afirma la construcción de la identidad social del ñuñoíno,

Mario Lillo señala que: "Si bien la obra fue escrita hacia fines de los años 70 y publicada en 1980, la aventura de amor romántico fallido sucede a mediados de la década del 50" (2013: 50). 
con una caracterización material de los objetos de los recién llegados. La carretela, con sus ruedas de madera y encintados metálicos, pasa a ser la proyección directa de la antítesis que representa a Constanza y su familia respecto de los valores encarnados por los habitantes tradicionales del barrio ${ }^{5}$. Más aún, los Glicker se encuentran encima del carretón, como si fuesen parte de esa misma materialidad que parece tan insultante. El esquema que se evidencia en la obra nos recuerda "el viejo análisis hegeliano del amo y el esclavo", en el cual la división de clases funciona de tal forma que los amos se encuentran condenados al idealismo por prescindir del mundo material, mientras que los esclavos son quienes conocen verdaderamente la realidad al lidiar cotidianamente con ella para satisfacer las necesidades de los primeros (Jameson 1986: 192). En Dónde estás, Constanza... el idealismo de los amos, expresado en la exposición de los valores de clase y en la descripción de algunas de sus prácticas, debe inducir al lector a conocer la composición de su mundo. Conforme a ello, descubriremos a través del relato que Alex no dista mucho de un adolescente corriente que falta al colegio, asiste al cine y a los lugares de moda. Será también un héroe capaz de dejarse llevar por el romanticismo y el incipiente impulso sexual, reflejándose en su huida con Constanza a la casa de la Reina.

En general, las diferencias entre protagonistas masculinos y femeninos aparecen en torno a la lógica de la comparación y el contraste. Conforme a ella, personajes, situaciones, relaciones y espacios se configuran en oposición a un otro que encarna cualidades totalmente antagónicas: es evidente que los Corsiglia son considerados extensiones naturales del paisaje, y por ello pareciese no ser necesario detenerse en la configuración de sus caracteres, mientras que los Glicker son extensiones de sus peculiares y precarias posesiones que, por ser ajenas, deben ser necesariamente mostradas.

En tal sentido, es imposible no establecer una asociación con la tesis de la armonía planteada en Mimesis (1942) por Erich Auerbach, cuando observa, respecto de la obra de Balzac, una coincidencia entre lo material y lo moral como rasgo inherente a la puesta en práctica del realismo literario (443). No obstante, aunque el principio de congruencia es similar, pues los personajes son configurados como extensiones de su medio, el código en el que se ocupa el recurso es totalmente diferente. Lo que ocurre con la obra de Rosasco es más bien una operación de clase, el narrador suple ciertas descripciones de los Corsiglia apelando a un saber universal del cual debiesen estar dotados los lectores, y que permitiría subentender que los rasgos del protagonista son coherentes con los de cualquier adolescente ñuñoíno de los cincuenta ${ }^{6}$, es el estatus del lugar aquel que define todo el actuar de Alex.

Por otra parte, en cuanto a la variable de género sexual y el tratamiento que le otorgan quienes adhieren a la visión autoritaria de la cultura, el principio que opera es básicamente el mismo que predomina en la cuestión de clase vista en el párrafo anterior. Se describe al sujeto femenino porque representa la disrupción; lo masculino, en cambio, al estar dentro de la norma, debiese subentenderse:

Valores que Mario Lillo define como los propios de un "ciudadano ejemplar" (2013: 68), teniendo en cuenta los criterios de la época.

6 Este rasgo que desde la distancia temporal puede ser leído como un sesgo en la obra, fue celebrado en su contexto de producción próximo. Fidel Araneda B., en Las Últimas Noticias, señaló lo siguiente: "Rosasco ha escrito una novela romántica muy original, nueva, pero no intrincada, muy simple, en la que ha logrado presentar un cuadro exacto de la sicología juvenil de un barrio santiaguino" (Cit. en Rosasco 1981: s/p). 
Bourdieu comenta que el orden social masculino está tan profundamente arraigado que no requiere justificación; se impone a sí mismo como autoevidente y es tomado como "natural" gracias al acuerdo "casi perfecto e inmediato" que obtiene, por un lado, de estructuras sociales como la organización social de espacio y tiempo y la división sexual del trabajo, y por otro, de estructuras cognitivas inscritas en los cuerpos y las mentes (Lamas 1999: 161).

Este principio se extiende, con algunos matices, al análisis de la obra de Campos Menéndez. De igual manera, ambos textos tienen como protagonistas uno o más sujetos de sexo masculino y la narración se construye desde esta perspectiva. La situación se condice con los principios ideológicos y sexuales del tradicionalismo que intentó fortalecer el régimen, basado en la preponderancia del hombre como sujeto productivo.

Centrémonos ahora en Águilas y cóndores. Aquí los héroes son configurados en torno a una matriz moral común: ambos son idealistas, nobles y gallardos, características inherentes, atribuidas por el narrador y los personajes, al linaje aristocrático otorgado por su directo parentesco con antepasados españoles, forjadores históricos del Reino de Chile. En la misma línea de los textos descritos anteriormente, la obra de Campos Menéndez también se construye en base a la polarización de personajes y situaciones, de forma que los dos héroes masculinos representan ideas radicalmente opuestas, que a su vez tendrán correlato en la conformación de sus personalidades. Mientras Rodrigo -héroe del realismo político- es un joven ordenado, estudioso, recto y conservador, Carlos - héroe patriota- es desordenado, temerario y liberal en sus ideas. Pese a esto, la obra da cuenta de un significativo contrapunto respecto de las dos anteriores: la pertenencia a un grupo homogéneo que representa la clase dirigente del país hace que el contraste sea siempre positivo. Más interesante aún es que la clase es concebida en términos de aristocracia, y por ende el grupo de pertenencia de estos héroes no posee rasgo negativo alguno: al estar determinado por sesgo "genético", hereditario, cualquier desliz significaría la irreparable degradación de la esencia chilena.

Existe un ánimo predominantemente conciliador en el texto, al menos entre los personajes que son parte de la elite, que toma forma en el discurso histórico recreado haciendo que las posturas de los héroes, aparentemente irreconciliables en la práctica, se encaucen casi de forma natural en una única e irrevocable respuesta a la problemática histórica que significa la guerra por la Independencia. Así lo asumen los personajes principales y así también se enseñará a la descendencia de los héroes varios años después de la muerte de Rodrigo:

-Papá cuenta que cuando tío Rodrigo agonizaba en sus brazos -recuerda Carlitos con voz conmovida-, le dijo que por fin comprendía que ambos hermanos eran uno solo, y que los ideales por los que combatieron eran los mismos.

-Sí... -murmura el sacerdote-. Eran en verdad uno solo. Dos cuerpos en una misma y noble alma... Yo no lo había advertido a pesar de que los conocí desde que nacieron y que fui su maestro y confesor. Sólo me di cuenta de ello cuando Rodrigo moría. Eran las dos caras de una misma medalla (Campos Menéndez 1986: 460).

Los caracteres que durante las más de mil páginas que constituyen el texto fueron expuestos como dicotómicos finalmente conducen hacia la representación de la síntesis de lo mejor del pueblo chileno, noble sustrato que daría forma a la República 
en ciernes. En tal sentido, es muy relevante poner de manifiesto que, aun cuando Águilas y cóndores abarca casi dos décadas y sería previsible un cierto desarrollo, los rasgos constitutivos de los personajes serán invariables, las aventuras y conflictos solo irán reforzando estas cualidades que se hacen visibles en ellos ya en la niñez, y que terminarán por convertirlos en héroes de guerra de intachable moral, únicamente homologables a padres de la patria como Bernardo O’Higgins, San Martín y Carrera. El sentido de la inmutabilidad se condice directamente con la construcción de lo chileno que subyace al contenido de la obra. La identidad nacional anhelada, encarnada en estos personajes modelo, se constituye esencialmente en base a criterios militares y raciales. Este primer rasgo se evidencia en la importancia que se le da a la carrera militar de los protagonistas, sea cual sea su bando, y a la de sus colaboradores más cercanos, con quienes establecen una alianza que se sostiene en valores como la gallardía y el altruismo.

Por otra parte, lo racial en el constructo de lo chileno interpela directamente al componente hispánico, fortaleciendo, junto a lo militar, la idea de una identidad de larga data arraigada en el espíritu nacional. La insistencia en la herencia española es probablemente aquello que impulsa al autor de Águilas y cóndores a plantear la relación entre realistas y patriotas en términos conciliatorios ${ }^{7}$. Sin embargo, el sentido de lo hispánico presente en la obra se afirma en la lectura que varios años antes había planteado Jaime Eyzaguirre respecto del tema, la cual asigna un doble influjo a esta tradición: "una conciencia de la dignidad humana y una conciencia de una ley moral que rige la vida internacional. De aquí deriva toda una concepción... de la justicia, de la organización social y de la moral, cuyo sustento último es la concepción cristiana de la vida" (cit. en Larraín 2001: 182).

La conjunción de ambos elementos (militar e hispánico) encauzada en el proceso de construcción de una nación independiente será determinante, como ya veremos, para comprender la división ideológica que enfrentará a los personajes en la novela.

Conforme a lo que hemos podido observar, los héroes de Águilas y cóndores son construidos en base a una rígida norma cuyo sustento es la clase social y la tradición aristocrática. En otras palabras, quienes componen el grupo son esencialmente burgueses blancos, de ascendencia española, salvo contadas excepciones, cuya fortuna proviene de la explotación de la tierra. Con todo, este canon incorpora un tipo de sirvientes leales a los intereses de los amos que, si bien se ubican en un segundo plano, son evaluados positivamente en el esquema configurado en la novela. En razón de esto, conviene tener en cuenta para futuras consideraciones que las oposiciones que veremos en el proceso de construcción de la otredad, si bien mantienen el esquema de división de clase, no lo convierten en el eje del conflicto, por el contrario, dicho rasgo se naturaliza y serán elementos más bien ligados a cuestiones éticas y filosóficas los que establezcan las distancias ideológicas entre héroes y antihéroes.

Observemos una cita en la que el padre de familia se dirige a sus hijos en la cena: "Don Fernando ha aprovechado una oportunidad más para hablar de genealogía, su tema favorito: -No deben olvidar, que por el lado de su madre descienden de un gentil hombre que allá por 1612 fue nada menos que Gobernador de estos Reynos" (Campos Menéndez 1986: 39). Es el mismo narrador quien destaca la insistencia en el orgullo por el linaje que dan a conocer los protagonistas. La idea se refuerza en la Nota Preliminar de la obra, en la cual se argumenta: "Nos parece necesario, también, señalar, en honor a la verdad, que los que fueron considerados irreconciliables enemigos por haberse enfrentado en cruentas batallas, estaban todos ellos animados del mismo fervor de servir a una digna causa. De manera que somos herederos, por ambos lados, en la contienda libertadora de la más noble ejecutoria de valor e hidalguía" (Campos Menéndez 1986: 10). 
La descripción del otro es también detallada en la medida que pretende reforzar las cualidades positivas del grupo que ocupa el foco de la historia. Aquí, nos es posible identificar dos niveles diferentes de personajes: los otros aliados, que son en su mayoría subordinados fieles y obedientes, cuyas características, si bien no son idénticas a las de sus amos, los acercan más que los distancian, ya que comparten un sistema valórico aprendido tras años de servidumbre; el segundo grupo es el de otros antagonistas, quienes habitualmente son personajes extranjeros o étnicamente diferentes: mulatos, mapuche y chuquisaqueños. Estos últimos, a diferencia de los mulatos y mapuche, comparten el lugar de clase de los Díaz de Huidobro y, en general, son aceptados y apreciados hasta cierto punto del desarrollo de la obra, por gran parte de los aristócratas criollos y españoles, pues logran incorporarse en las trincheras realista y patriota sin dificultades. El problema central con estos personajes no es, por tanto, el lugar que ocupan en el entramado social ni tampoco la hegemonía pigmentocrática, pues la subordinación basada en estos principios se encuentra igualmente en ambos grupos: Isidro, el mulato, obedece a Álvaro, amo chuquisaqueño, tal y como Toño, un típico roto, obedece al patriota Carlos Díaz de Huidobro. La real diferencia entre otros aliados y otros antagonistas es que los primeros, al igual que sus amos, buscan el bien de la comunidad, sea entendida como reino (realismo) o como nación independiente (patriotas), mientras que el antagonista persigue la gloria y gratificación individual.

En otras palabras, la ideología en el texto adquiere forma en el conflicto entre lo público y lo privado, entre el bien propio y el bien común. Sin duda, es la reflexión que hacen los héroes en torno al problema lo que genera la empatía con el bando rival en la lucha política. Para ellos, como ya hemos consignado, lo que importa son los alcances y expectativas que ofrece el proyecto político por el que se lucha:

- ¿Sabes, Manuel? Me han quedado dando vueltas tus últimas palabras -confidencia Carlos-. Y cuando hablabas, mi pensamiento se fue a mi hermano Rodrigo. Él no está con nosotros. Eso me dije... pero me doy cuenta, ahora, solamente ahora, que él, también a su modo, está en la causa... No sé cómo explicarte... Se me ocurre que él es tan chileno como nosotros... Pero piensa de otra manera, tan opuesta, que está en la trinchera contraria. Y eso no puede ser... no tiene una explicación lógica... ¿No será que lo que él sueña, piensa y quiere, sea también parte del Chile nuevo, ese que estamos formando? El alma de una nación... tiene tanto de pasado como de porvenir... El presente es sólo un puente entre esas dos realidades (Campos Menéndez 1986: 283-284).

En este caso, Carlos reconoce tanto en su causa como en la de su hermano el anhelo de un bien mayor, evidentemente más noble que el de los verdaderos antagonistas. La oposición encuentra su correlato histórico en el presente de producción de las obras, como evidenciaremos en las próximas páginas, en la división entre corporativistas e individualistas que se genera entre los adherentes al régimen.

Nos encontramos frente a dos configuraciones distintas de héroes. Por un lado la obra de Rosasco presenta un sujeto que, si bien es tentado por la pasión, actúa guiado por el pragmatismo y la búsqueda de la satisfacción personal de sus deseos y aspiraciones. Dicha característica se refleja no solo en el desarrollo de las relaciones amorosas sino que también en la forma en la que el personaje es construido en el relato mismo. La economía de recursos en la descripción que se hace de él es una muestra elocuente de esto; la indeterminación se suple con la orientación de la representación 
hacia lo desconocido que, como vimos, apela a referentes culturales de clase. Por otra parte, los héroes de Campos Menéndez obedecen a un criterio moralizante de lo que efectivamente significa ser chileno, por ello los mecanismos que se despliegan en la obra apuntan a eliminar cualquier atisbo de duda respecto de lo positivo y lo negativo que se espera de cada uno los lectores.

\section{LOS HÉROES DEL ROMANCE}

Georg Lukács ha definido al héroe mediocre como aquel individuo "correcto pero no propiamente heroico" (1966: 33) en el que se expresan realísticamente tanto los rasgos humanos, decentes y atractivos como las limitaciones propias del sujeto común de la clase media. La categoría ha sido construida como un contrapunto con el héroe venerado por el romanticismo, que encarnaba una serie de virtudes que lo convertían en un ser ideal, valiente, capaz de explicar por sí mismo la esencia de una época (Lukács 1966: 35-40). Pese a que la categoría de Lukács está pensada para el análisis de la novela histórica, considero pertinente extrapolarla a nuestro estudio, en su sentido más simple y no con la complejidad que le otorga ser un mediador en las crisis históricas, pues establece una distinción que ilustra bastante bien los rasgos del héroe del romance, género predominante en las obras que estamos revisando, y lo distancia del héroe de la novela moderna, identificado más bien con el sujeto medio que adquiere visibilidad y representación seria en cuanto aparece este género. En tal sentido, la aplicación de los conceptos nos ayudará a visibilizar los matices que se presentan en la construcción de los textos y, conjuntamente, pondrá de manifiesto las implicancias políticas que poseen estos mecanismos de representación en las obras.

Conforme a lo dicho, es claro que el sujeto representado en la novela de Rosasco responde a las características del tipo mediocre, mientras que los de Campos Menéndez al tipo romántico. Más aún, como hemos adelantado, la elección de un determinado héroe en estos casos da cuenta de la concepción de la sociedad que subyace a cada uno de los autores. Las formas de enfrentar las crisis amorosas que definen el curso de cada una de las historias son vivas muestras de ello.

La renuncia de Alex a la aventura emprendida con Constanza, si bien puede ser interpretada como pura cobardía, tal y como lo hace la joven al notar que la voluntad de su amado empieza a flaquear, es reivindicada por el propio personaje como acto de madurez, y así se lo explicará a su tío en uno de los párrafos finales de la novela:

-Su papá y unos carabineros nos fueron a buscar. Ella quería que huyéramos y, bueno, no sé si arrancó sola, no sé.

-Cómo, ¿no estabas ahí mismo?

-Sí, claro, pero yo resolví volver por mi cuenta...

-Te dio miedo

-No, tío, estoy seguro de que no era miedo, fue peor que eso, mucho peor, porque la abandoné y no sentía miedo, simplemente todo me pareció de repente algo imposible (Rosasco 1981: 104).

A la voluntad romántica que anima la huida se termina por superponer una racionalidad pragmática que ya había comenzado a operar en el mismo momento de la fuga, y que se incrementa cuando el joven observa las precarias condiciones del 
refugio que les serviría como hogar. La materialidad, que en el transcurso de la obra parece ser ajena a las consideraciones que el protagonista hace en torno a su amada, aparece en escena al emprender la aventura y va incrementando su peso conforme llegan a vivir a la casona.

El proceso, además, se encuentra acompañado por la transformación que sufre Constanza a ojos de Alex. Ella misma es despojada de su estampa etérea, convirtiéndose en una carga insoportable. A partir de ahí, lo posible y lo imposible cobran un nuevo sentido para el protagonista, quien se vuelve un observador minucioso de su propio acontecer: la utopía representada por Constanza cobra vida en un lugar físico marcado por las carencias; el proyecto, entonces, no posee ningún sustento para ser llevado a cabo y, por tanto, el cambio de lo conocido a lo desconocido pierde todo sentido, logrando imponerse el criterio pragmático que debiese prevalecer en el criterio del joven conforme al lugar de clase que ocupa.

En el desenlace, Alex descubre que el amor que creía sentir no era más que un capricho vano que lo desvía de su natural derrotero. Por eso, superada la aventura, el protagonista vuelve a su vida previa al romance, reafirmando, ya desde la experiencia, la validez de sus valores y formación: predomina en él una sensación "bienhechora" que le inunda el corazón (Rosasco 1981: 112).

En un plano radicalmente opuesto se encuentran Rodrigo y Carlos, protagonistas de Águilas y cóndores. Al asumir una postura histórico-política asumen también que esta trae asociada múltiples dificultades, incluyendo entre ellas la posibilidad de morir en aras de su causa. La nobleza en la determinación política se replica en la forma de enfrentar el sino amoroso; los hermanos que se disputan el amor de Angélica están genuinamente dispuestos a aceptar la elección de la joven por uno de los dos. Así se evidencia en la escena del matrimonio entre Rodrigo y María Angélica; aparece Carlos, quien durante el enlace se encontraba en clandestinidad por ser periodo de Reconquista, y felicita a la joven pareja:

-¡Hermano! ¡Te estás jugando el pellejo! -exclama con los ojos llenos de alegría y asombro, Rodrigo.

- ¿Cómo no iba a estar en tu casamiento? Te felicito, Rodrigo... ¡Sé que somos uno solo!dice con emoción en la voz- ¡Elegiste la misma novia que yo!

-Gracias, Carlos. Nadie me pudo haber hecho un regalo más lindo que el tuyo... con tu presencia... ¡Cuídate y que Dios te ampare! -exclama María Angélica con un brillo de emoción en sus bellos ojos (Campos Menéndez 1986: 235).

En el texto de Campos Menéndez se cumple el mismo principio que Doris Sommer observó en los romances del siglo XIX: "La pasión erótica no era ese exceso socialmente corrosivo que debía ser sujeto a disciplina en algunas novelas europeas, sino más bien la oportunidad (no solo retórica) de mantener unidos a grupos heterodoxos, fueran estos regiones competitivas, intereses económicos, razas o religiones" (Sommer 1991: 31). La lógica conciliatoria que plantea la obra cimenta el camino para que la disputa por el amor se resuelva de modo que la resignación y empatía se superponen a los sentimientos egoístas. Lejos de abandonar el amor, lo que hace Carlos es ocultarlo y restringir sus desbordes para no importunar a su hermano y a María Angélica. Por su parte, Rodrigo no demuestra incomodidad alguna frente al hecho de que su rival amoroso se presente en el día de la boda y haga notar que sigue queriendo a la que es ahora su esposa; esta actitud termina por equiparar la bondad 
y entereza de los dos personajes. Conviene acotar que este actuar se da solo entre pares chilenos pues, tal y como señalamos más arriba, frente a un tercer contrincante chuquisaqueño los personajes se enfrentan física y verbalmente en más de una ocasión. La diferencia obedece, tal y como ya se dijo, a los intereses perseguidos por cada contrincante. Mientras Carlos y Rodrigo aman a la joven desinteresadamente, Álvaro esconde una segunda intención, relacionada con el ansia de poder, venganza y dinero. Como veremos en las próximas páginas, la división que se hace en el relato encuentra su génesis en el contexto de producción de la obra.

Con todo, la mezcla entre pasión y nobleza encarnada por estos jóvenes termina por configurar al típico héroe romántico asociado al género del romance, opuesto casi por naturaleza al héroe mediocre asociado a las representaciones burguesas en las que predomina una racionalidad pragmática por sobre el desborde heroico y pasional del romanticismo. Lukács señala que los sucesos que permiten entender históricamente la división entre ambos héroes se relacionan directamente con los procesos revolucionarios que vivió Europa entre los siglos XVII y XVIII. En el caso de Francia, por ejemplo, el teórico húngaro señala que los intelectuales de la reacción crean una engañosa imagen idílica de la sociedad de la Edad Media, que tendrá un impacto profundo en la novela romántica de la Restauración. Pese a que la imagen que se construye del periodo revolucionario será tergiversada "debemos reconocer que también es una expresión históricamente necesaria. La nueva etapa del desarrollo, que comienza con la Restauración, obliga a los defensores del progreso humano a crear una nueva armadura ideológica" (Lukács 1966: 25).

Haciendo las salvedades pertinentes, la obra de Campos Menéndez adquiere un sentido similar en nuestra historia: el autor se encuentra en España prestando servicios en la embajada chilena, observando, probablemente con cierta nostalgia, la realidad nacional completamente permeada por la influencia extranjera.

Si bien el antagonismo entre estas ideas es parte de un debate que se suscita históricamente entre los siglos XVIII y XIX en Europa, y por tanto podría parecernos totalmente fuera de lugar en tres obras chilenas de finales del siglo $\mathrm{XX}$, veremos que lo que sostiene la abismal distancia entre un modo y otro es un principio bastante similar al que se manifiesta en estos pasados siglos. Lo que ocurre con el texto de Rosasco no es otra cosa que el despliegue del ideario neoliberal en la producción cultural, mientras que con Campos Menéndez asistimos a la muestra ya decadente de la resistencia nacionalista encabezada por el grupo más conservador de la derecha chilena. En ese sentido, la configuración de uno u otro héroe es sintomática de las diferencias ideológicas que pugnan en el mismo campo.

Bernardo Subercaseaux profundiza en esta diferencia, haciendo hincapié en las consecuencias que ella tuvo en el campo editorial chileno, estableciendo la existencia de grupos con distintas intencionalidades y visiones políticas. Estos pueden sintetizarse de la siguiente forma: un primer grupo, compuesto por dos facciones ligadas al polo conservador (ya sea por la filiación religiosa o militar), y en el que prima el interés por la cultura como manifestación de la esencia de la nación, base para la formación de la nueva chilenidad en la que se sintetizaban todos aquellos principios tradicionales que la historia recientemente superada había intentado anular. Como es de suponer, el Estado era considerado el principal motor de difusión y expansión de la cultura, y, dado que sus fines eran superiores e intangibles, no debía ser concebida en términos de rentabilidad económica (1984: 72-73). 
El segundo grupo está compuesto por el ala neoliberal ${ }^{8}$, asociada a una burguesía moderna basada en el capital financiero internacional. Desde esta vertiente se concibe la cultura como bien transable, similar a otros, y que requiere, por lo tanto, ser desarrollado con criterios mercantiles y de eficiencia empresarial. De acuerdo con estos criterios, instaurar una lógica de mercado, promover políticas de autofinanciamiento y prescindir del subsidio estatal, pasan a ser aspectos centrales en la gestión de la empresa (1984: 73).

Como es sabido, la disputa terminará con la imposición indiscutida del último grupo, generando bastante contrariedad entre los primeros, quienes durante los tres primeros años de dictadura creían haber puesto sólidos cimientos para consolidar su propuesta. Más allá de evaluar aquí los resultados y proyecciones sociales de cada vertiente, importa destacar que, asociadas a ellas, existía unas concepciones de sujeto o individuo que, como ya hemos señalado, se condicen con la construcción de los personajes centrales de cada texto.

Hombres, burgueses en edad productiva o bien pronta a serlo, sin ninguna característica excepcional son, sin duda, los héroes pensados desde el paradigma liberal, es decir desde la perspectiva del individuo. Detengámonos en los postulados de Friedrich Hayek (1948), economista asiduamente citado por la dictadura, para comprender a qué nos referimos cuando hablamos del héroe mediocre en estos términos.

Con todo, casi no hay duda de que la principal preocupación de [Adam] Smith no era tanto lo que el hombre eventualmente pudiera lograr con lo mejor de sí, sino darle la oportunidad de realizar el mínimo daño con lo peor de sí. No resulta exagerado sostener que el mérito principal del individualismo que él y sus contemporáneos defendieron, radica en que es un sistema en el cual los hombres malos pueden provocar un mínimo daño. Es un sistema social que no depende para su funcionamiento de encontrar hombres buenos para ponerlo en marcha, ni de que todos los hombres sean mejores de lo que son ahora, sino que hace uso de todos los hombres en toda su complejidad y variedad, que a veces es mala y a veces buena, a veces inteligente y a menudo hasta estúpida (Hayek 1948: 11).

Visto así, la construcción de Alex como personaje representante de una clase y espacio determinado adquiere coherencia respecto de un escenario mayor, que es el de la cosmovisión del sujeto en el marco ofrecido por el paradigma económico social dominante en nuestro país por aquellos años ${ }^{9}$ el joven no debía por qué ser particularmente bueno, puesto que ello no alteraría su propio derrotero. Por el contrario, lo genuinamente relevante es, a partir de este pensamiento, actuar de manera funcional a las lógicas éticas y morales impuestas por el modelo.

La búsqueda de la consumación del romance en un espacio ajeno al cotidiano responde a estos mismos parámetros orientados hacia la minimización de cualquier efecto negativo asociado al ejercicio de la libertad individual: la aventura amorosa

Se debe tener en cuenta que la expresión de estas facciones tampoco es homogénea. Como bien señala Isabel Jara (2015), existen determinados grupos dentro de cada facción que tendrán más o menos notoriedad según el periodo que se esté analizando. Véase: "Editora Nacional Gabriela Mistral y clases sociales: indicio del neoliberalismo en la retórica de la dictadura chilena".

9 El período que va entre 1979 y 1982 es caracterizado por Constable y Valenzuela como una fase de liberalización profunda de la economía, inspirada en las ideas de Friedrich Hayek (Cit. en Jara 2015: 508). 
emprendida tiene lugar lejos de casa (la comuna de La Reina), puesto que la distancia geográfica permite la invisibilización de cualquier tipo de evidencia capaz de testimoniar un eventual fracaso. Con esto se excluye, a la vez, cualquier posibilidad de conflicto o alteración de la cotidianeidad. Conjuntamente, la elección de escenarios pequeños como una comuna dentro del gran Santiago o un pueblo de interior es una variable significativa en nuestro análisis, puesto que las acciones de los protagonistas tendrán repercusiones igualmente aisladas e intrascendentes respecto de un lugar mayor. La operación es aquí la explicación del comportamiento social a partir del individuo mediocre en un contexto puntual y limitado, mientras que el héroe romántico representado en Águilas y Cóndores es la encarnación del espíritu de la nación, transhistórico y universal ${ }^{10}$, ejemplo al cual debiese aspirar ser todo chileno.

Tomando distancia de la lógica liberal, los héroes de Campos Menéndez parecen entenderse mejor en el escenario que supone la temprana influencia del corporativismo franquista en nuestro país. La convergencia entre las ideas nacionalistas y principios neoliberales en el ámbito socioeconómico fue observada con especial atención por los chilenos golpistas, quienes encontraron en la idea de democracia orgánica ${ }^{11}$ un sustento para la acción política que proyectaban realizar. En el campo cultural la mirada hacia el pasado clásico y la revaloración de sus formas, como plataforma para la formación de un nuevo deber ser nacional, fue considerado un modelo inapelable para quienes estaban pensando, desde el gobierno, la cultura en Chile, lo cual se tradujo en una continua exaltación de la herencia española ${ }^{12}$ en diferentes espacios y tipos de producción artística. Sin embargo, como bien hace notar Isabel Jara, "la aplicación de un liberalismo económico a ultranza en todas las esferas sociales desde fines de los años 70- produjo la reacción no sólo de los opositores sino que de las propias filas tradicionalistas o nacionalistas del régimen, que entendieron que estaban en peligro los "valores tradicionales chilenos"' (2006: 277). Las posturas que surgieron en torno a la polémica fueron, en general, bastante duras y señalaban a los asesores tecnócratas del gobierno como los principales causantes del problema. No obstante Enrique Campos Menéndez, colaborador fiel del régimen, puso el foco en el exterior:

10 Rasgo que también expresa a través del género ensayístico: "Campos Menéndez habla desde un nacionalismo (retórico) que se extiende a toda la historia del país. 'Nacionalista fue, sin duda, el araucano que defendió con su sangre la ruca en que vivía, como el español que bautizaba con la suya el camino de su aventura"” (Pinedo 2005: 115).

11 Pese a que el franquismo y sus ideas no son el tema central de reflexión en nuestro trabajo, me parece fundamental repasar, brevemente, la ambigüedad que reviste el concepto político que intenta replicar la dictadura chilena. La democracia orgánica "Según Linz, carecía, sin embargo, de una ideología precisa, se movía por criterios pragmáticos debido a que una élite de expertos en economía y administración — que no pertenecían a la Falange...- se habían convertido en ministros y altos cargos públicos. Contra Linz, sin embargo, podría argumentarse que existía una ideología clara de 'solidaridad nacional', aunque el lenguaje para defenderla evolucionó desde el anticuado corporativismo católico (y nacionalsindicalismo falangista) al "moderno" lenguaje de la ciencia económica. Pero la realidad distaba mucho de la ideología, ya que, a pesar de que ciertamente existía un "pluralismo limitado", la cuestión era: ¿pluralismo para quién?” (Martínez y Roca 1988: 26).

12 Isabel Jara destaca el hecho de que la "hispanidad" es, en el contexto dictatorial, un valor en sí mismo, pues "penetró los símbolos patrios de la Independencia y otros episodios republicanos... asociados a la historia militar por los uniformados, convirtiendo a la identidad colonial en la forjadora de la "verdadera" identidad republicana y actual" (2006: 319). Conjuntamente, este valor fue fundamental en la concepción esencialista de la cultura nacional pues fortaleció la idea del "alma propia" de cada pueblo, la cual se alimentaba de "imágenes que suponen un tipo peculiar de sangre o una herencia biológica" (Larraín 2001: 182), lo cual se condice directamente con la configuración de los personajes de Campos Menéndez. 
El peligro consiste en que Chile... de pronto se abrió al mundo por intermedio de las comunicaciones y los medios económicos. Esto ha producido un deslumbramiento, una supervaloración de lo extranjero, tanto en el terreno de las ideas como de las cosas y las costumbres. Esta invasión viene envuelta de un bellísimo ropaje, de tal manera que es muy difícil distinguir lo bueno de lo malo... El valor fundamental de la sociedad chilena es el haber mantenido inalterables ciertos principios que se basan en la esencia de la sociedad cristiana occidental y mantienen viva la célula de la familia, que es donde radica la fuerza espiritual de Chile... El segundo valor sería el coraje que tiene el chileno para defender lo que venera. El chileno es pacífico siempre y cuando no intenten amagar sus principios esenciales. Una tercera virtud destacable es el amor que siente por todo lo que constituye su ser esencial, es decir, su tierra, su historia y sus instituciones (cit. en Jara 2006: 280).

Cuando el autor entrega estas declaraciones nos encontramos a fines de los años setenta, momento en el cual se pensaba que la arremetida del mercado aún podía ser contenida, razón por la cual las críticas, además de visibilizar el problema, buscaban proponer soluciones y formas para revertir lo que estos sujetos consideraban como la degradación del sentir patriota. Ya en 1986, fecha de publicación de su obra, cuando el neoliberalismo es una realidad concreta, los recursos que pone en práctica Campos Menéndez parecen ser la última apelación a la memoria emotiva del chileno, recordándole por medio de sus dos héroes la existencia de esos principios esenciales que, aunque venidos a menos, se encontraban todavía vivos ${ }^{13}$. Pese a que la obra no contó con mayor publicidad, como sí lo tuvo años antes su predecesora, Los pioneros (Campos Menéndez 1983) ${ }^{14}$, importa señalar que la obra de Campos Menéndez contó con la mejor de las publicidades "indirectas" que se podía tener en la época: la entrega del Premio Nacional de Literatura a su autor el mismo año en que se publicaba. A pesar de que el premio le costó más críticas negativas que respaldo por parte de sus pares y de los académicos, significaba, desde la perspectiva oficialista, inscribirlo en los anales de la literatura chilena. Esta situación tuvo en su momento un valor muy diferente al que podríamos darle hoy, teniendo en cuenta el destino de la obra, ya que en 1986 aún existía, por parte de las autoridades, la intención de proyectar su gobierno por varios años más. De hecho, hay quienes afirman que, luego de ser publicada, hubo un intento fallido de llevarla a la televisión (Montealegre 2007: 7), cuestión sumamente significativa respecto de las decisiones que en materia cultural consideró la dictadura y, también, un rasgo muy elocuente en lo que se refiere a la relación entre literatura y medios de comunicación masivos ${ }^{15}$.

En un plano más profundo, el ejemplo que ofrece la obra se explica en el contexto propio de aquel sector más tradicional de la derecha chilena, ligado históricamente al

13 Situación similar se da cuando en 1974 reedita a Nicolás Palacio. Con ella "se intentaba apelar a los instintos primarios de la ciudadanía para revitalizarla en un nacionalismo que sí compartían los militares, y que intentaron sobreponerlo a un neoliberalismo que lo negaba en la práctica" (Pinedo 2005: 115).

14 Para la realización de este trabajo se revisaron los segmentos de "Artes y Letras", de El Mercurio, comprendidos en las publicaciones aparecidas entre 1973 y 1990. Una de las pocas referencias en la prensa será una crítica de Braulio Arenas, hecha en El Mercurio el 27 de Julio de 1986, en la que se destaca la amenidad del relato y su capacidad conciliatoria en la lectura de la historia nacional (E5).

15 Suponemos con bastante certeza que el impacto del texto fue bastante limitado en comparación a lo que ocurre con la obra de Rosasco. Uno de los problemas con los que nos encontramos al hacer este tipo de evaluación es el oscurantismo respecto de datos objetivos como tirajes y ventas; problema que hace notar Enrique Lafourcade, en 1986, al preguntarse por el actual estatus de la literatura en Chile en El Mercurio (D12). 
devenir político de la nación, cuyo origen se remonta a las primeras décadas de nuestra vida republicana. Campos Menéndez, nieto de un marqués español, recurre a esta herencia para justificar el dominio, o más bien, la necesidad de dominio de su clase y con ello del proyecto político que sostiene a Chile como nación con determinadas características: "Mi padre fue también quien me enseñó a amar a España y a Chile; quien me hizo sentirme orgulloso de la nobleza de la vieja estirpe y al mismo tiempo de ser igual a todos en una Patria nueva que se ennoblece gracias a la igualdad de todos" (Campos Menéndez 1980: 17).

El anacronismo de la novela es, entonces, una muestra del compromiso del escritor ${ }^{16}$ con la idea de un Chile que ha ofrecido históricamente igualdad para todos, y que, por supuesto, se ve amenazado en el presente de la escritura por la pérdida de control por parte del Estado, que trae aparejado el predominio del mercado y la intromisión de una cultura ajena a la hispana. No obstante, la pregunta que parece rondar las apreciaciones de Campos Menéndez es por el tipo de igualdad a que se refiere cuando habla de Chile. Desecharemos aquellas variables referidas a la clase, lo étnico y lo religioso, por ser elementos que, en el pensamiento del escritor, ejercen su influjo y establecen sus normas de manera incuestionable en la sociedad. En tal sentido, la igualdad que observa y aspira mantener el autor es una igualdad homogeneizante, en la que la comunidad comprendida es aquella que ha internalizado, acepta y reproduce las relaciones de subordinación que mantienen el orden oligárquico garantizado por el ejército.

En consecuencia, la intención que se esconde tras el reciclaje de fórmulas que son ajenas aun al paréntesis que representa la dictadura respecto del escenario general de producción literaria, guarda cierta relación con la interpretación que hace Grínor Rojo (2014) en torno al título de la novela Los convidados de piedra (Edwards 1978). Me explico: en su análisis, Rojo señala que la alusión a Los convidados de piedra en el título del texto nos habla del continuo retorno, en distintas circunstancias y con distintas generaciones, del sector social dominante del país frente a cualquier amenaza, del orden transhistórico construido por los mismos (s/p). Algo así como un recordatorio constante de la dificultad que implicaría enfrentarse a ellos en algún intento de subversión. Pues bien, considero que la operación de Enrique Campos Menéndez es similar en cuanto su objetivo es mostrarles cómo se construyó y consolidó el orden que permitía el correcto funcionamiento del país, en diferentes épocas y escenarios, a quienes, siendo parte del grupo dominante, pusieron en práctica, durante la dictadura, un nuevo tipo de dominación atentatorio contra la tradicional pero efectiva esencia del proyecto de los forjadores. En otras palabras, busca revivir a los convidados de piedra que la tecnocracia había convertido en obsoletos.

Conforme a la lógica de la comparación y contraste que anteriormente hicimos notar respecto del texto, Carlos y Rodrigo se erigen como la representación romántica del bien nacional frente al mal extranjero, por supuesto, se excluye del grupo a los españoles, quienes son vistos como forjadores espirituales e intelectuales de la

\footnotetext{
Una de las características que diferencia a Campos Menéndez de sus pares comprendidos en este estudio, es, precisamente, la idea del compromiso que manifiesta abiertamente el autor con el proyecto político de la dictadura puesto que encarna, al menos inicialmente, los valores defendidos por el autor: "La reminiscencia de mis orígenes, su perspectiva a lo largo de los años; la precisa definición de la tarea hacia la cual he orientado mi existencia, me autorizan a declarar que soy un escritor comprometido; integralmente comprometido conmigo mismo, con mi tiempo... y, en consecuencia, con mi patria, con su ámbito y su destino" (1980: 33).
} 
nación. La alusión al influjo negativo, como insistentemente he señalado, se relaciona en la obra de manera directa con la cuestión racial; sin embargo, algunos pasajes de esta introducen sutilmente la crítica a los referentes angloamericanos en la temprana conformación cultural chilena. Ejemplo de ello es el juicio que se hace de la opinión del cónsul estadounidense Joel Roberts Poinsett, quien defiende la Independencia latinoamericana argumentando que "[La América] es el país donde únicamente debe reinar la libertad" (Campos Menéndez 1986: 29). Algunos párrafos más adelante aparecerá O’Higgins cuestionando estas palabras: “-Señores: vengo a comunicarles que se acabó este carnaval que se está haciendo de la revolución. La libertad, la igualdad y la fraternidad... necesitan del orden y la jerarquía... y el mando" (Campos Menéndez 1986: 31). La evaluación de los valores considerados extranjeros será, como norma en la obra, negativa.

Esta notoria diferencia entre la configuración de los héroes no ocurre de manera aislada en los textos; la elección de los espacios, como hemos visto, sumada a la del escenario temporal proyectan las mismas filiaciones ideológicas; los años cincuenta y la penetración de la cultura norteamericana de masas por medio del cine y la música colman las páginas de Dónde estás, Constanza..., mientras que las de Águilas y cóndores se orientan al rescate de figuras como Moratín, Cervantes y Goya que, como hemos señalado, se condicen con el rescate de una alta cultura y de un hispanismo de raigambre esencialista.

\section{EL CONFLICTO EN EL CAMPO CULTURAL: REVERSO Y ANVERSO}

Antes de discutir, a modo de cierre, las repercusiones que tienen las diferencias que hemos logrado evidenciar en la configuración del campo literario y cultural, creo relevante destacar que aun cuando en este espacio coexistieron en conflicto las sensibilidades nacionalista, de "alta cultura" y neoliberal, hubo ciertos préstamos y cruces ideológicos innegables (Jara 2015: 517) que permiten establecer una matriz común de análisis. De hecho, extrapolando la reflexión que hace Isabel Jara en torno a la labor de la Editora Nacional Gabriela Mistral, es posible señalar que "las potencialidades técnicas y epistémicas de los libros residían en la aptitud de presentar, sintetizar o simplificar conceptos y significados complejos para efectos de instrucción o difusión" (Jara 2015: 522). En consecuencia, aquí radica la importancia de la fórmula del romance en las obras revisadas: su empleo busca reflejar ciertas cualidades, aptitudes y costumbres anheladas por el régimen (Frye 1991: 43).

El valor que tienen los matices que aparecen en las obras está, en primer lugar, en la confirmación de la existencia de un campo como tal, y luego, en que ponen en evidencia que tal espacio es un poco más complejo de lo que podría parecernos a primera vista. Existe conflicto y lucha de intereses que se plasma en los intentos de validación que llevan a cabo los actores implicados en esta esfera. Con esto no pretendo sugerir que el campo afín a la dictadura fuese un espacio rico y profundo de discusión en el que prevalecía el legítimo derecho al disenso; quienes efectivamente levantaron críticas más duras respecto del régimen o sus personeros fueron marginados. Es el caso de Roque Esteban Scarpa, director de la DIBAM entre 1973 y 1977, que tras dejar el cargo critica duramente las políticas censuradoras del régimen, situación que lo lleva a ser excluido de las esferas próximas al poder central (Jara 2006: 269). 
Tampoco mi intención es desconocer la influencia efectiva que tuvo el campo de poder en el cultural: basta solo recordar la existencia de la censura previa vigente hasta 1983, que incomodaba incluso a los escritores afines al régimen, para desechar tal idea. Sin embargo, me parece innegable que el carácter heterónomo (Bourdieu 1997: 321) que le es inherente a este campo se encuentra mediado por un conflicto no menor, en el que se ponen de manifiesto no solo cuestiones estéticas sino que también el ideal de sociedad que se espera tras el proceso de refundación de la nación.

La total apropiación de los principios neoliberales por parte de la cúpula dirigente, y con ello el repliegue del Estado en la educación y la cultura, significó un duro golpe para algunos intelectuales que habían adherido al régimen pensando en que el mando militar se traduciría en el predominio de una visión integrista de la sociedad. Esta situación los llevó a criticar abiertamente la gestión gubernamental en dichas materias ${ }^{17}$. En contraste, la postura de los autores cuyas obras hemos analizado acá tendió más bien hacia la validación en algunos casos, y en otros, hacia la obediencia y lealtad, poniéndose de manifiesto no solo en su ejercicio como funcionarios o asesores de gobierno, sino que también en la defensa de la obra de la dictadura en términos ideológicos como es el caso de Rosasco ${ }^{18}$, o bien en una reorientación de las críticas como ya vimos con Campos Menéndez.

El clima que prevaleció en el grupo fue el de la aceptación del experimento ideológico que sintetizaba los principales rasgos de las ideas en pugna en la época, encauzado en la lectura hayekeana del liberalismo. Su particularidad fue, tal y como lo señala Jorge Larraín, la capacidad de postular un neoliberalismo conservador basado, por un lado, en la interpretación evolucionista de la cultura, que lo hace respetuoso de la religión y la tradición y, por otro, en la creencia de que liberalismo no debe ser homologado a la democracia, ya que el pensamiento de la mayoría no es necesariamente correcto (Larraín 2001: 218).

Me interesa hacer notar que el autoritarismo tradicionalista, como principio unificador de los adherentes al régimen, tiene un correlato tangible en el campo cultural a través de la elección del género literario: el romance, con su estructura estable en el tiempo (Frye 1991: 12), ofreció a estos autores la posibilidad de abordar simplificadamente el presente, como una dimensión unívoca, despojándolo de toda su complejidad inherente. No obstante, lo novedoso aquí es el hecho de que las hibridaciones que aparecen en él estarán siempre relacionadas con la postura que adopta cada autor frente a la elección del modelo de desarrollo más pertinente para el país. El análisis de los héroes es un ejemplo bastante gráfico de ello. Solo para ilustrar la idea, diremos que, finalmente, lo que se cuestiona en las obras jamás es la capacidad del hombre como sujeto productivo, tampoco está en juego la visión esencialista de la identidad (la cual en todos los casos viene dada, desde el

Un ejemplo interesante, quizás el más recordado debido a su trascendencia nacional e internacional, es el que ofrece el historiador chileno Mario Góngora, quien ya desde los años sesenta advertía de los peligros asociados a la penetración irrestricta del neoliberalismo. En consonancia con ello, su apoyo a la junta militar y a la dictadura obedecía, en parte, al carácter nacionalista que ésta, a imitación del gobierno franquista, pregonaba en sus discursos. No obstante, más tarde, cuando el neoliberalismo es una realidad concreta en nuestro país, acusará directamente a la tecnocracia (gubernamental) de la disolución de los valores y de la cultura nacional" (Jara 2006: 278).

18 Recordemos que el autor se define abiertamente como un liberal: "Es evidente que el socialismo tiene dentro de sí un humanismo que no tiene el régimen liberal, que es el sistema que yo apoyo desde un punto de vista político. Pero el sistema liberal tiene eficacia. Eso significa que produce riqueza" (Lazzara 2002: 194). 
nacimiento, por el lugar de origen, la genética o la posición ocupada en el entramado social) (Larraín 2001: 25), menos aún la idea de lo femenino. Por el contrario, lo que realmente genera la crisis es la misión que se le asigna al sujeto protagonista respecto de su medio y las repercusiones que tendrá su accionar en cuanto este sea o no modelo moral para sus pares.

\section{OBRAS CITADAS}

Arenas, Braulio. 1986, 27 de julio. “Águilas y Cóndores”. El Mercurio: E5.

Auerbach, Erich. 1942. Mímesis. La representación de la realidad en la literatura occidental. Trad. J. Villanueva y E. Ímaz. 1996. México: Fondo de Cultura Económica.

Bourdieu, Pierre. 1997. "El punto de vista del autor. Algunas propiedades generales de los campos de producción cultural". Las reglas del arte. Génesis y estructura del campo literario. Trad. Thomas Kauf. Barcelona: Anagrama.

Campos Menéndez, Enrique. 1986. Águilas y cóndores. Santiago: Universitaria. . 1980. Quién es quién en las letras chilenas. Santiago: Editorial Nascimiento.

Frye, Northrop.1991. La escritura profana. Trad. Edison Simmons. Caracas: Monte Ávila.

Hayek, Friedrich. 1948. "Individualismo: el verdadero y el falso". Centro de Estudios Públicos. 1986. Chile. $\mathrm{N}^{\mathrm{o}} 22$ : 1-28.

Jameson, Fredric. 1986. "La literatura del tercer mundo en la era del capitalismo multinacional”. Trad. Ignacio Álvarez. Revista de Humanidades 23: 161-193. 1989. Documentos de cultura, documentos de barbarie. La narrativa como acto socialmente simbólico. Trad. Tomás Segovia. Madrid: Visor.

Jara, Isabel. 2006. De Franco a Pinochet: el proyecto cultural franquista en Chile, 1936-1980. Santiago: Editado por Universidad de Chile.

. 2015. "Editora Nacional Gabriela Mistral y clases sociales: indicio del neoliberalismo en la retórica de la dictadura chilena". Historia, vol. II. n 48: 505-535.

Lafourcade, Enrique. 1986, 18 de mayo. "Para una literatura con 'Apeirón”". El Mercurio: D12.

Lamas, Marta. 1999. "Usos, dificultades y posibilidades de la categoría género". Papeles de población. Vol. 5, nº 21, julio-septiembre: 147-178.

Larraín, Jorge. 2001. Identidad Chilena. Chile: LOM Ediciones.

Lazzara, Michael. 2002. Los años del Silencio: conversaciones con narradores chilenos que escribieron bajo dictadura. Chile: Editorial Cuarto Propio.

Lillo, Mario. 2013: Silencio, trauma y esperanza: novelas chilenas de la dictadura 1977-2010. Santiago: Ediciones Universidad Católica de Chile.

Lukács, Georg. 1966. "La forma clásica de la novela histórica”. La novela histórica. Trad. Jasmin Reuter. México: Era.

Martínez, Joan y Jordi Roca. 1988. "Economía política del corporativismo en el Estado español: del franquismo al postfranquismo". ReiS 41: 25-62.

Montealegre, Jorge. 2007. "Identidad y representaciones en un mundo globalizado". Polis 18: $1-13$.

Pinedo, Javier. 2005. "El pensamiento de los ensayistas y cientistas sociales en los largos años 60 en Chile (1958-1973). Los herederos de Francisco A. Encina".Athenea. 492: 69-120.

Regis, Pamela. 2007. A Natural History of the Romance Novel. Philadelphia: University of Pennsylvania Press.

Rojo, Grínor. 2014. Los convidados de piedra o del retorno (feroz) del reprimido oligárquico. N.P.

Rosasco, José. 1981. Dónde estás, Constanza... . Santiago: Editorial Andrés Bello. 
SOBRE HÉROES E IDEOLOGÍAS: LA CONSTRUCCIÓN DEL SUJETO EN LA LITERATURA PERTENECIENTE

AL CAMPO CULTURAL AFÍN A LA DICTADURA

1984. “¿Qué preparan los escritores chilenos?”. El Mercurio. 8 de abril: E5.

Sarlo, Beatriz. 2011. El imperio de los sentimientos. Narraciones de circulación periódica en la Argentina (1917-1927). Buenos Aires: Siglo XXI editores.

Sommer, Doris. 2004 [1991]. Ficciones fundacionales. Las novelas nacionales de América Latina. Trad. José Leandro Urbina y Ángela Pérez. Bogotá: Fondo de Cultura Económica.

Subercaseaux, Bernardo. 1984. La industria editorial y el libro en Chile (1930-1984). Santiago: CENECA. 
